\title{
O teatro no Ricardo III, de Tónan Quito
}

JOSÉ PEDRO SOUSA

Título: Ricardo III. Texto: William Shakespeare. Tradução: Rui Carvalho Homem. Direcção artística: Tónan Quito. Interpretação: António Fonseca, Márcia Breia, Miguel Loureiro, Miguel Moreira, Miguel Sobral Curado, Paulo Pinto, Raquel Castro, Romeu Runa, Sofia Marques, Teresa Sobral, Tónan Quito (e Carolina Cabrita, Leonor Cabrita, Maria Abreu, Mariana Rala, Nuno Represas, Tiago Carvalho). Interpretação musical ao vivo: Gonçalo Marques (trompete), João Lopes Pereira, Joel Silva (percussão). Cenografia: F. Ribeiro. Figurinos: José António Tenente. Desenho de luz: Daniel Worm. Música original: Gonçalo Marques (trompete) e João Lopes Pereira (percussão). Desenho de som: Pedro Costa. Assistência de encenação: Filipa Matta. Coordenação do elenco juvenil: Luís Godinho. Produção: HomemBala/TNDMII/Centro Cultural Vila Flor/Stage One. Local e data de estreia: Sala Garrett do Teatro Nacional D. Maria II, 15 de Outubro de 2015.

Comecemos pelo princípio. A tradução em verso da peça shakespeariana, da autoria de um catedrático com provas dadas como é Rui Carvalho Homem, é de uma harmonia e beleza poética que, sem desvirtuar as ambiguidades do texto de partida, contribui para a criação de um texto actual e compreensível para o leitor/público contemporâneo, cumprindo, assim, os desígnios do «Projecto Shakespeare» do CETAPS": «oferecer uma imagem actual e coerente da obra dramática de Shakespeare [...] [trazendo-a] para o século XXI, tornando-[a] inteligível para a nossa cultura e para o nosso idioma [...]» (Shakespeare, 2015: 7-8). Há, porém, aqui e ali, certas falas cuja sintaxe poderia, a meu ver, ter sido «desambiguada» de modo a facilitar o trabalho de quem diz e o de quem escuta as palavras traduzidas do bardo.

Seria contraproducente avaliar em separado o cenário e o guarda-roupa deste Ricardo III, pois eles potenciam-se mutuamente, para além da qualidade estética individual de cada um, enquanto partes integrantes de um todo. $\mathrm{O}$ cenário, de F. Ribeiro, cria um ambiente sombrio e obscuro que poderá remeter, pelo seu despojamento, para uma certa ideia de «espaço vazio», sublimada com mestria pelo uso de milhares de pedaços ou restos de pneu triturado que cobrem toda a superfície do palco e que conferem uma enorme plasticidade e dinâmica ao jogo 


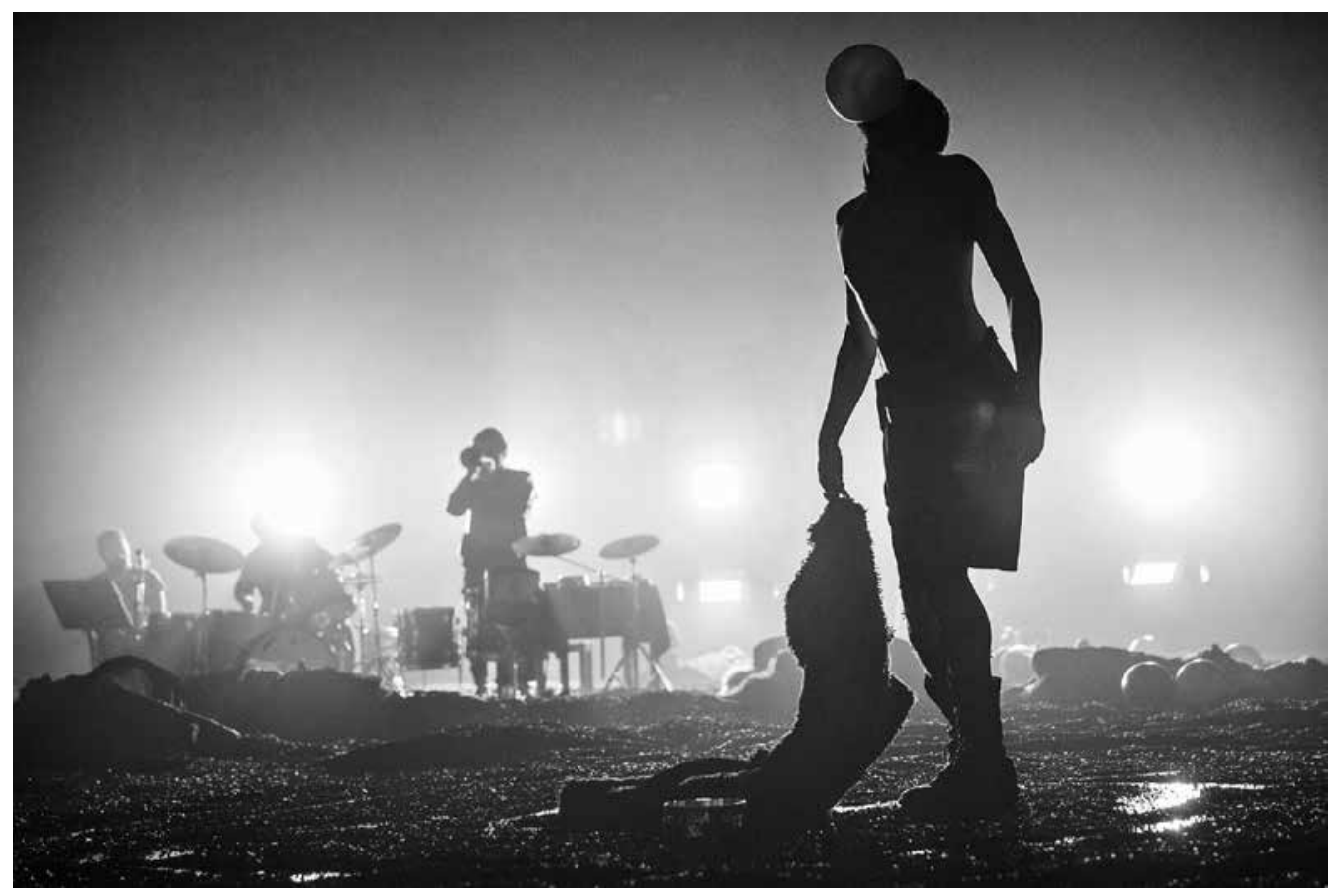

RICARDO III, DE WILLIAM SHAKESPEARE, ENC. TÓNAN QUITO, TEATRO NACIONAL D. MARIA II, 2015 (ROMEU RUNA), [F] FILIPE FERREIRA cénico. Esta beleza inquietante do cenário encontra nos figurinos punk de José António Tenente o seu par ideal. A plasticidade e a qualidade dos materiais, o rigor do corte e a paleta de cores fazem deste guarda-roupa um inexcedível exemplo da arte de bem vestir actores no teatro. Cenário e figurinos são, em suma, impactantes em termos plásticos e muito eficazes cenicamente, moldando-se sem dificuldade às exigências de uma encenação que tanto faz transitar por vários actores a «corcunda» do protagonista, como assinala cada morte perpetrada no decurso da acção com o levantar de uma campa feita dos restos de pneu que cobrem o palco.

No domínio da luminotecnia, o desempenho de Pedro Alves revela tamanha sensibilidade e versatilidade no uso da cor, da intensidade da luz e dos diversos meios técnicos de que dispõe, demonstra uma tal perspicácia e bom gosto na exploração do contraste entre luz e sombra, que não está longe de ser genial. Neste Ricardo III a luz adapta-se à(s) cena(s) criando quadros dignos dos mais célebres museus de pintura; convocando, de maneira exímia, ambientes tão diferentes entre si quanto expressivos das diversas «atmosferas» do espectáculo (desde a mais ténue luz crespuscular de um diálogo intimista à mais intensa 


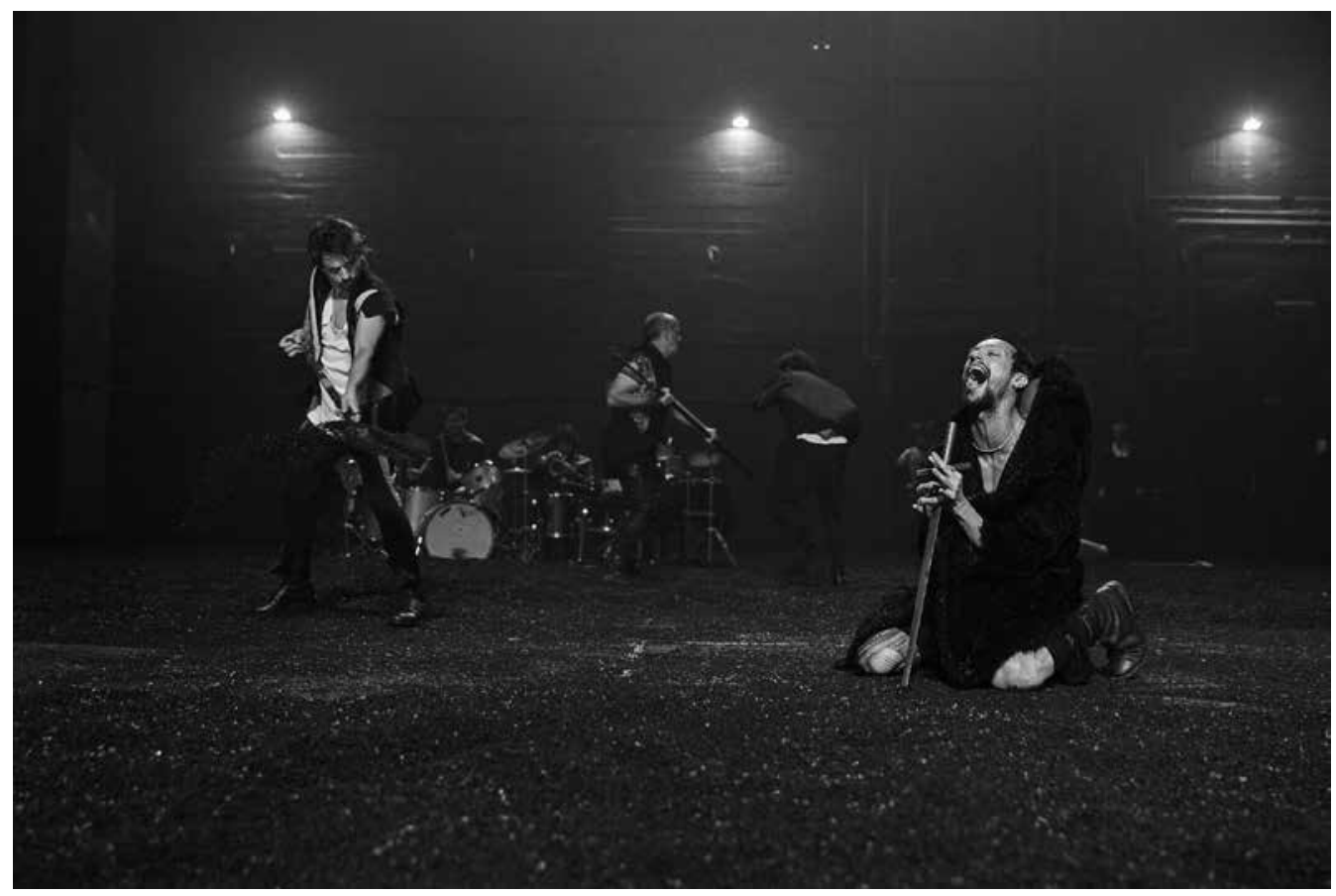

RICARDO III, DE WILLIAM SHAKESPEARE, ENC. TÓNAN QUITO, TEATRO NACIONAL D. MARIA II, 2015 (MIGUEL MOREIRA E ROMEU RUNA), [F] FILIPE FERREIRA

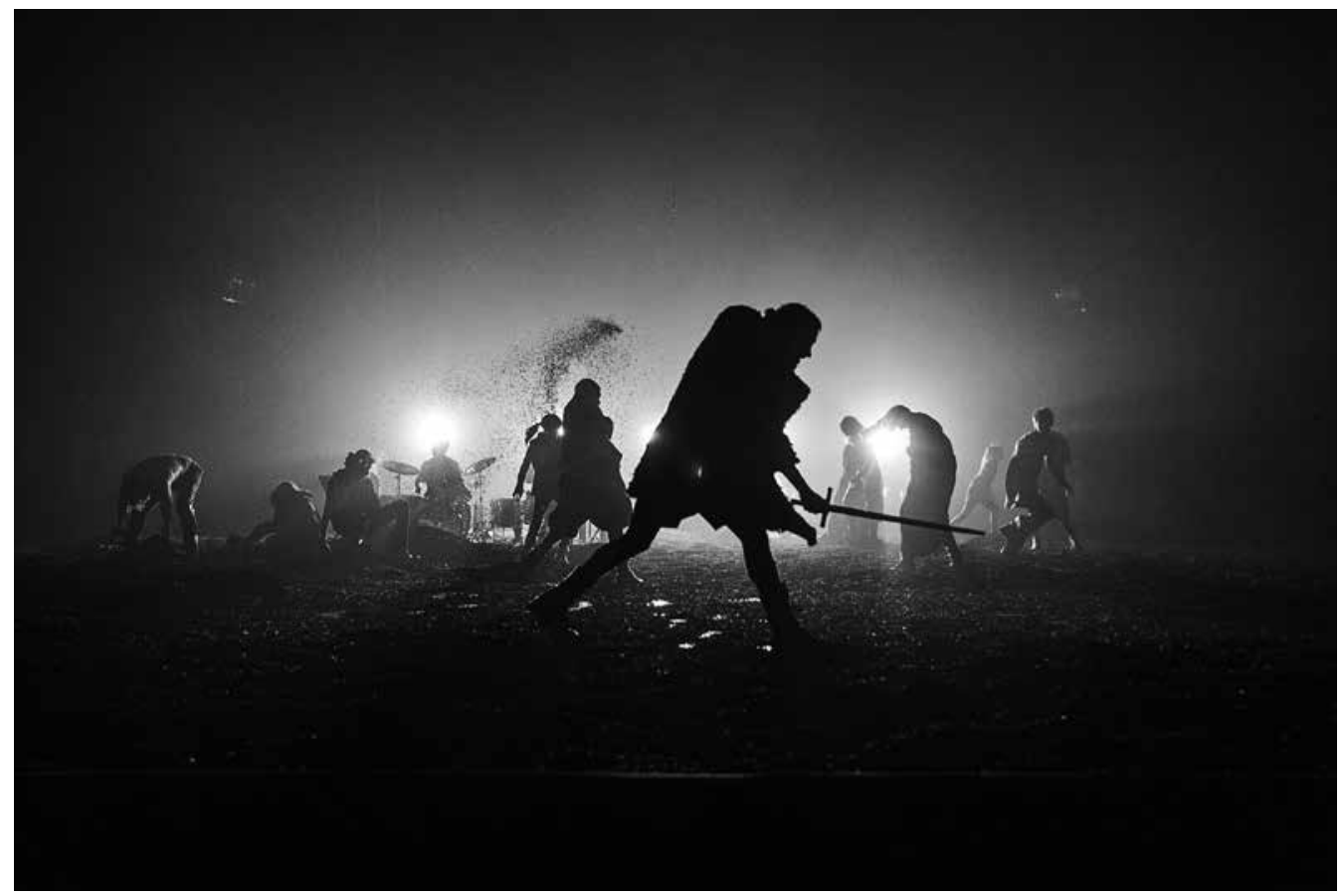

RICARDO III, DE WILLIAM SHAKESPEARE, ENC. TÓNAN QUITO, TEATRO NACIONAL D. MARIA II, 2015, [F] FILIPE FERREIRA 
e fulgurante iluminação da batalha final, e culminando com uma poderosa e comovente contraluz que acentua a intensidade dramática do «monólogo coreográfico» com que termina a função). No silêncio do teatro, diante do fumo feito orvalho que a fria luz branca adensa, Romeu Runa é - mais do que representa o expirar de um cavalo (criatura em troca da qual, como bem se sabe, Ricardo III daria de bom grado, naquele instante, todo o seu reino).

Sobre um fundo musical entre o rock e o metal, recuperado qual refrão em diversos momentos da performance, a sonoplastia Pedro Costa (desenho de som), Gonçalo Marques e João Lopes Pereira (música original) - integra-se de forma orgânica na acção. Os executantes (Gonçalo Marques, trompete; João Lopes Pereira e Joel Silva, percussão) contracenam com os actores, ora tirando proveito das suas «alfaias», ora usando da palavra. Pontualmente, os intérpretes aproximam-se dos músicos e experimentam os instrumentos, gestos simples mas que revelam bem a unidade intrínseca entre todos os ofícios (e oficiais) deste Ricardo III.

A qualidade artística de cada um dos elementos do espectáculo antes aludidos e a forma harmónica como interagem entre si e se fundem num todo uno, coerente e consistente derivam, pelo menos em parte, de uma encenação estruturada e inteligente. Basta dizer que as dinâmicas criadas em palco através da palavra dita e do movimento dos corpos no espaço, com o importante contributo da sonoplastia, desenho de luz, cenografia e figurinos, são de tal forma eficazes, que fazem passar em menos de um fósforo as duas horas e meia de duração deste espectáculo. Todavia, há que reconhecer que a encenação não apresenta uma leitura particularmente inovadora da obra de Shakespeare. Em linhas gerais coincide com a interpretação tradicional, mais focada na natureza ardilosa e manipuladora do protagonista, enquanto motor da acção, do que em qualquer outro elemento da trama. $O$ facto de a epígrafe do programa (p. 3) ser um excerto das teses de Jan Kott, publicadas há mais de 50 anos em Shakespeare Nosso Contemporâneo (1964), denuncia esse lado algo datado e, nesse sentido, pouco original desta produção.

Numa análise mais fina das opções dramatúrgicas, destacam-se dois aspectos principais. Por um lado, a ênfase na ideia de que Ricardo III somos, ou podemos ser, todos nós, concepção que é traduzida para a cena, nomeadamente, pela transição deste vilão entre os vários actores do elenco, que em determinados 
momentos da representação o interpretam. Por outro lado, a perspectivação do protagonista como «o grande encenador», consentânea com a habilidade com que Ricardo III manipula as demais personagens da peça como se de marionetas se tratassem, é veiculada por um vasto conjunto de «estratégias» que visam suspender a ilusão dramática e pôr em evidência perante o espectador a natureza lúdica e ilusória desse jogo de «faz de conta» que é o teatro.

O elenco, bastante heterógeneo, integra várias gerações de intérpretes em diferentes fases da sua carreira e com distintas formações (teatro, dança e música). Se, inevitavelmente, este melting pot de experiências profissionais e vivências pessoais e artísticas resulta numa certa disparidade dos registos de representação, podendo até evidenciar a desigualdade, em termos qualitativos, das interpretações, também é verdade que esta opção contribui para acentuar as duas concepções estruturantes desta encenação acima mencionadas. De facto, refutar a propensão uniformizadora na direcção de actores que privilegia a homogeneidade de registos de interpretação não só permite contrariar o processo de alienação do espectador na teia ficcional como reforça a universalidade do carácter de Ricardo III, que, como já se disse, é interpretado neste espectáculo tanto por principiantes quanto por profissionais mais experientes, sejam homens ou mulheres, jovens ou mais maduros.

Uma vez que a disparidade das representações é propositadamente assumida e acaba por adensar a pluralidade de leituras deste espectáculo, afigura-se inútil destacar outro nome deste elenco além do de Romeu Runa. Em grande medida a centralidade de Ricardo III tanto na peça como nesta encenação já fazia prever o destaque, na cena, do seu intérprete, mas o elevadíssimo grau de qualidade da sua performance, tanto em termos da expressão corporal do actor/personagem como ao nível da expressão oral (o texto dito por Runa, sem exageros na interpretação e demonstrando um domínio perfeito dos tons, ritmos, pausas e silêncios, é um trabalho digno de louvor) supera quaisquer expectativas. Romeu Runa é uma força da natureza que só por este desempenho bem merece figurar para sempre no panteão dos grandes actores portugueses. 


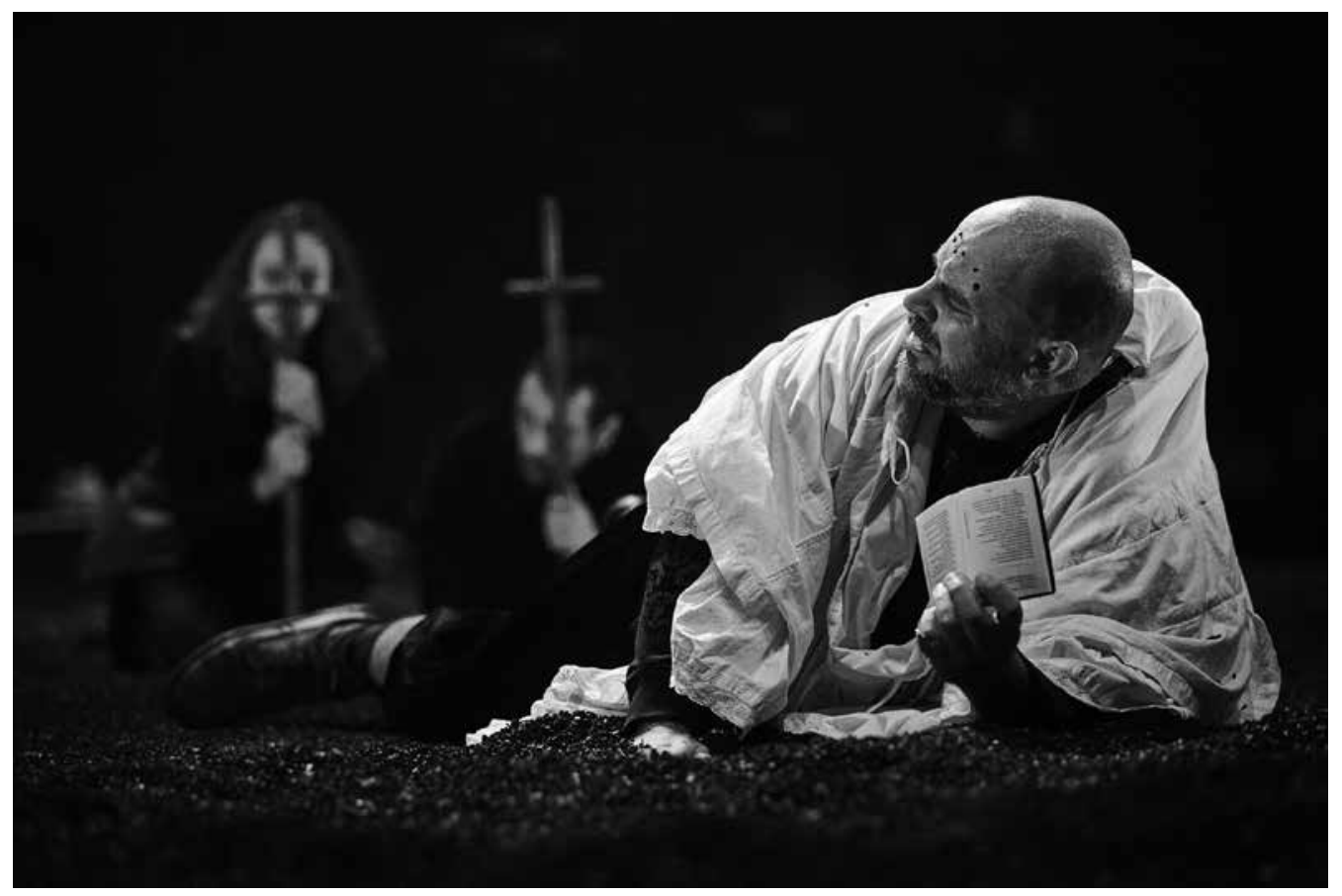

RICARDO III, DE WILLIAM SHAKESPEARE, ENC. TÓNAN QUITO, TEATRO NACIONAL D. MARIA II, 2015 (RAQUEL CASTRO, ROMEU RUNA E MIGUEL LOUREIRO), [F] FILIPE FERREIRA

Kо T T, Jon (1964), Shakespeare Nosso Contemporâneo, trad. Norberto Ávila, Lisboa, Portugália [1961]. SHAKE SPEARE, William (2015), Ricardo III, trad. Rui Carvalho Homem, Lisboa, Relógio D’Água, 2015. 